\title{
Immunopathological aspects of trypanosomal meningoencephalitis in vervet monkeys after relapse following Berenil ${ }^{R}$ treatment
}

\author{
A. A. Poltera ${ }^{1 \star}$, P. D. Sayer ${ }^{2}$, G. Brighouse ${ }^{3}$, D. Bovell ${ }^{4}$ and W. Rudin ${ }^{5}$ \\ ${ }^{1}$ CIBA-GEIGY R-1241.2.01, CH-4002 Basel, Switzerland; ${ }^{2}$ Kenya Trypanosomiases Research Institute, \\ Kikuyu, Kenya; ${ }^{3}$ WHO Immunology Research and Training Centre, Geneva, Switzerland; ${ }^{4}$ International \\ Laboratory for Research on Animal Diseases, Nairobi, Kenya; ${ }^{5}$ Swiss Tropical Institute, CH-4051 Basel, \\ Switzerland
}

\begin{abstract}
Four quarantined vervet monkeys were treated with intramuscular Berenil ${ }^{\mathbb{R}}$ in patent CNS infection after experimental trypanosome inoculation with Trypanosoma brucei rhodesiense or T. brucei brucei. All four animals relapsed in the post-therapeutic survival time of 37 to 209 days when they had fully developed meningoencephalitis in histological sections with the presence of interstitial intracerebral trypanosomes, which were confirmed in two monkeys by electron microscopy. In both, sequential samples of the serum and cerebrospinal fluid were analysed for circulating immune complexes, immunoglobulins and albumin. From these results the intracerebral IgG synthesis and the impairment of the blood-brain-barrier were calculated, both being present in advanced infection. Circulating immune complexes were present in the serum, but could not be demonstrated in the cerebrospinal fluid. The monkey model therefore permits the study of various aspects of cerebral trypanosomiasis. Berenil ${ }^{\mathrm{R}}$ treatment is inefficient in patent $\mathrm{CNS}$ infection and leads to a protracted, less virulent disease course with terminal meningoencephalitis and intracerebral "persister" trypanosomes. This drug-induced trypanosome shift with meningoencephalitis could be used for chemotherapeutic purposes to test new compounds in late stage disease.
\end{abstract}

\section{Introduction}

Recurrence of trypanosomes in a host treated with adequate doses of trypanocides is definitely called a relapse, provided that after therapy the host remains outside the endemic area or the experimental model precludes the possibility of reinfection.

Some trypanocides can mask an ongoing central nervous system ( $=$ CNS) involvement by trypanosomes. This has been shown in human African trypanosomiasis (= HAT) by CALWELL (1937) and by various authors (NEITZ \& MCCULLY, 1971; JENNINGS et al., 1979; POLTERA et al., 1981, 1982) in experimental African trypanosomiasis (=EAT). Since trypanosome-infected vervet monkeys were available from a chemotherapeutic project, selected biological samples were taken for analysis. This report provides some preliminary data in relation to circulating immune complexes (= CIC), autoantibodies, blood-brain-barrier, site of trypanosomes in the CNS and the topography of histological changes within an organ. Berenil ${ }^{p}$ (diminazene aceturate) has been reported to be curative in trypanosome infected vervets (SCHMIDT \& SAYER, 1982), but the present observations prove that relapses do also occur after Berenil $^{\mathrm{R}}$ in vervet monkeys.

\footnotetext{
Materials and Methods

Arimal

Four Cercopithecus aethiops (vervet monkey) were prepared for the experiment as already reported (SCHMIDT \& SAYER, 1982),

\section{Trypanosomes}

The trypanosome used was a stabilate from Trypanosoma bruce thodesiense (= TBR, EATRO 1989) or from $T$. brucei brucei ( $=$ TBB, GUMS I) as reported by SCHMIDT \& SAYER (1982) and POLTERA et al. (1980) respectively. The inoculum consisted of $10^{4}$ trypanosomes per monkey.
}

\section{Laboratory Methods}

The laboratory methods for monitoring the disease have been used, as already described (SCHMIDT \& SAYER, 1982). $\mathrm{CIC}$ were determined by the $\mathrm{C}_{1 \mathrm{q}}$ binding assay reported by LAMBERT et al. (1981) including a modification for the cerebrospinal fluid $(=\mathrm{CSF}$ ) determination. In the latter, a description of the determination of other constituents such as albumin and immunoglobulins can also be found.

Drug

Berenil $^{\mathrm{R}}$ was used to prevent death after more than 50 days of infection when animals were acutely ill. The dosage was $5 \mathrm{mg} / \mathrm{kg}$ per day during three to four days by intramuscular injection. Monitoring of such treated vervets continued, including repeated lumbar puncture with subsequent centrifugation and mouse inoculation (SCHMIVI \& SAYER, 1982).

\section{Histology}

Samples were collected during the post-mortem. Three coronal sections of the fresh brain permitted access for electron microscopy ( $=\mathrm{EM}$ ) sampling (see below).

Fixation with formalin, embedding in paraffin and staining with haematoxylin and eosin were performed according to standard histological techniques.

\section{Electron Microscopy}

Sampling of brain blocks at the lateral choroid plexus, hypocampus, thalamus and pons was done immediately after death in two monkeys. After fixation in $2.5 \%$ glutaraldehyde the samples were micro-dissected under a stereomicroscope in $0.2 \mathrm{M}$ cacodylate buffer. After postfixation in $2 \%$ osmium tetroxide the specimens were blockstained in $2 \%$ uranyl acetate in $70 \%$ acetone before further dehydration and embedding in Epon according to routine procedures (RUDIN et al., 1983). Semi-thin sections were cut for orientation using Azur II Methylene blue stain. Subsequently thin sections were analysed using a Philips EM 300.

*address for correspondence 


\section{Autoantibodies}

Fresh frozen mouse brain was cut sagittally at $4 \mu$ (Poltera et al., 1980). Test-serum or test-CSF from trypanosome-infected vervet monkeys - collected while in relapse and shortly before death-was diluted $(1: 10,1: 100)$ and exposed to the mouse brain sections. Fluorescentconjugate, coupled with antihuman IgG, diluted $1: 10$, was used for staining (Nordic Laboratories). Slides were examined under a Leitz orthoplan photomicroscope using the equipment for immunofluorescence.

\section{Blood-brain-barrier}

Blood-brain-barrier impairment ( $Q$ alb) and intracerebral IgG synthesis ( $Q$ IgG/Q alb) were calculated with the same formulae as referred to by LAMBERT et al. (1981).

\section{Results}

The relevant data of four trypanosome-infected vervet monkeys are presented in Table $I$. It is apparent that the survival time after Berenil ${ }^{\mathrm{R}}$ treat- ment varied between 37 and 209 days. Histologically all four monkeys showed fully established meningoencephalitis (Fig. 1) with moderate to marked perivascular cuffing, microglial reaction and occasional plasma cells free in the neuropil. However, the choroid plexuses showed only mild inflammatory cell infiltration. The trypanosomes were seen diffusely scattered throughout the brain, but not in the choroid plexuses. This interstitial and extracellular presence was confirmed by electron microscopy in two vervets (Fig. 2), from which biological samples were also obtained (Monkey No. 33 and No. 52).

Fig. $3 a+b$ depict the sequential events before and after treatment with Berenil ${ }^{R}$ in two monkeys (Nos. 33,52 ) in relation to parasites in the blood and CSF and to CIC in the serum and CSF. It is evident that CIC level off after therapy but increase subsequently as relapse is fully established.

Table 1-Trypanosoma infected vervet monkeys and treatment failure with Berenil ${ }^{R}$

\begin{tabular}{ccccccc}
\hline $\begin{array}{c}\text { Animal } \\
\text { No. }\end{array}$ & Trypanosome & $\begin{array}{c}\text { Administration } \\
(\text { day) }\end{array}$ & $\begin{array}{c}\text { Dose } \\
(\mathbf{m g} / \mathbf{k g})\end{array}$ & $\begin{array}{c}\text { Tr.m. } \\
\text { Duration } \\
\text { (days) }\end{array}$ & $\begin{array}{c}\text { Dead } \\
\text { (day) }\end{array}$ & $\begin{array}{c}\text { Post-therapeutic } \\
\text { survival } \\
\text { time (days) }\end{array}$ \\
\hline 30 & TBR & 28,63 & 5 & $2 \times 4$ & 68 & $37,(2)$ \\
33 & TBB & 64 & 5 & 3 & 113 & 46 \\
52 & TBR & 64 & 5 & 3 & 148 & 81 \\
T9 & TBR & 89 & 5 & 4 & 301 & 209 \\
\hline
\end{tabular}

Key: TBR $=$ EATRO $1989=T . b$. rhodesiense

TBB $=$ GUMS $1=T$. b. brucei

i.m. = intramuscular

* = after inoculation

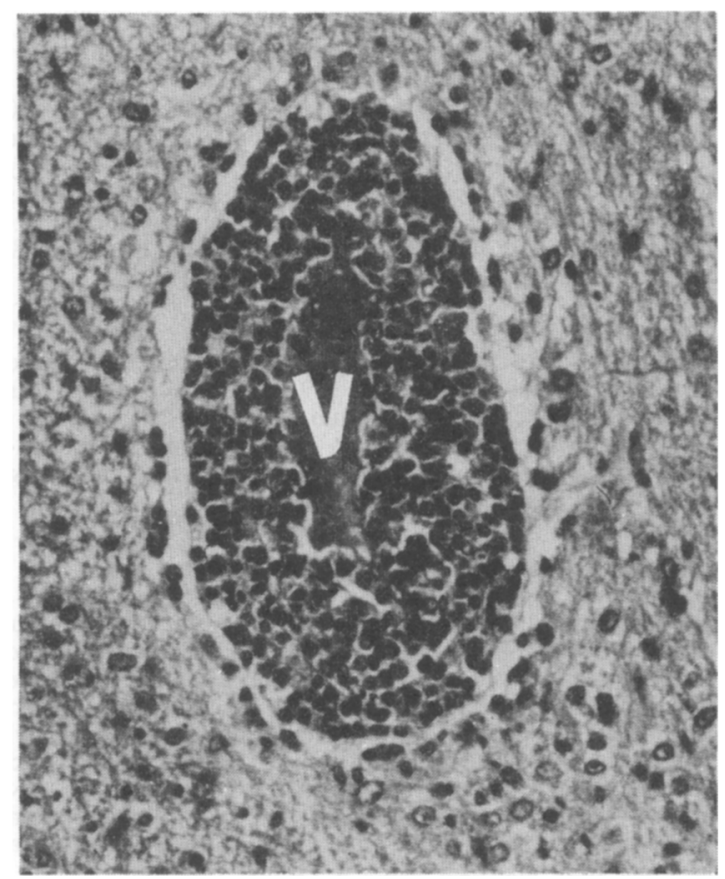

Fig. 1. Monkey No. 52. Marked encephalitis with perivascular accumulation of mononuclear cells. $V=$ Vessel lumen. $H \& E$, $\times 40$.

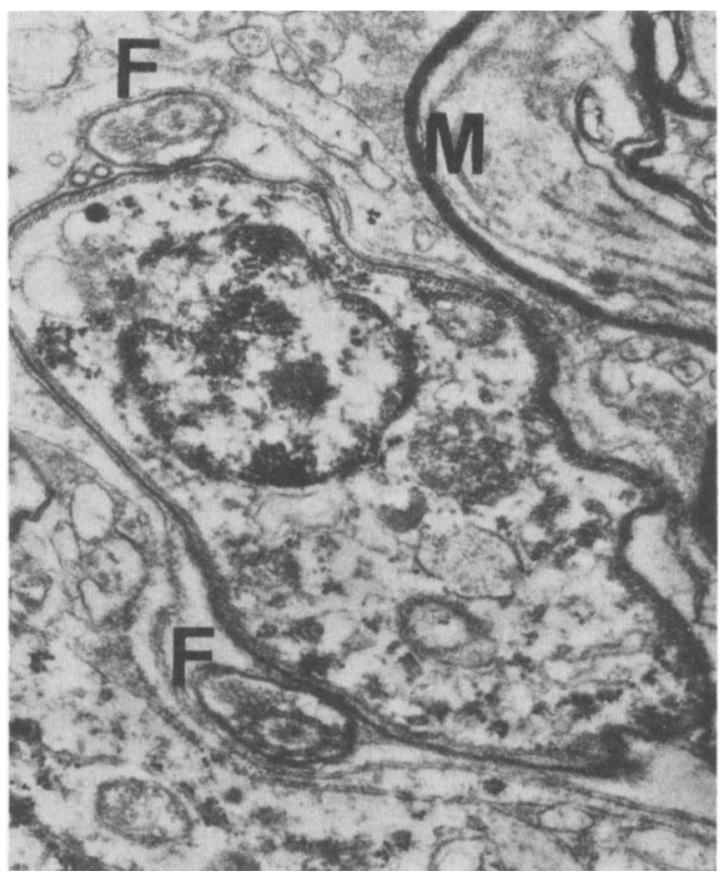

Fig. 2. Monkey No. 52. Single flagellated (F) trypanosome next to a myelin sheath $(-M)$ in the meuropil. Note that interstitial extracellular localization. EM, $\times 17000$. 

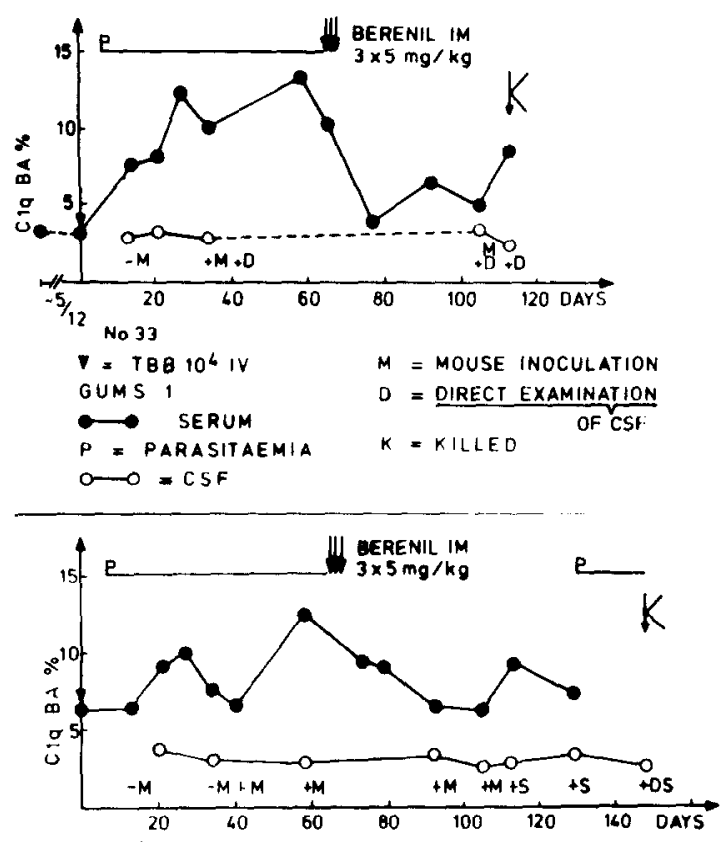

No 52

$$
\begin{aligned}
& \nabla=\mathrm{TBR} 10^{4} \mathrm{~K} \\
& \text { EATRO } 19 \text { R9 } \\
& \longrightarrow \text { = SERUM } \\
& P=\text { PAR ASITAEMIA } \\
& \bigcirc-O=C S F \\
& M=\text { MOUSE INOCUL ATION }
\end{aligned}
$$

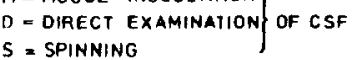

$$
\begin{aligned}
& K=K I L L E D
\end{aligned}
$$

Fig. 3. Fig. 3a: Monkey No. 33. Fig. 3b: Monkey No. 52. Two graphs illustrating the occurrence of parasites and circulating immune complexes in serum and cerebrospinal fluid related to post-inoculation time and Berenil ${ }^{\mathbf{R}}$ admuinistration.

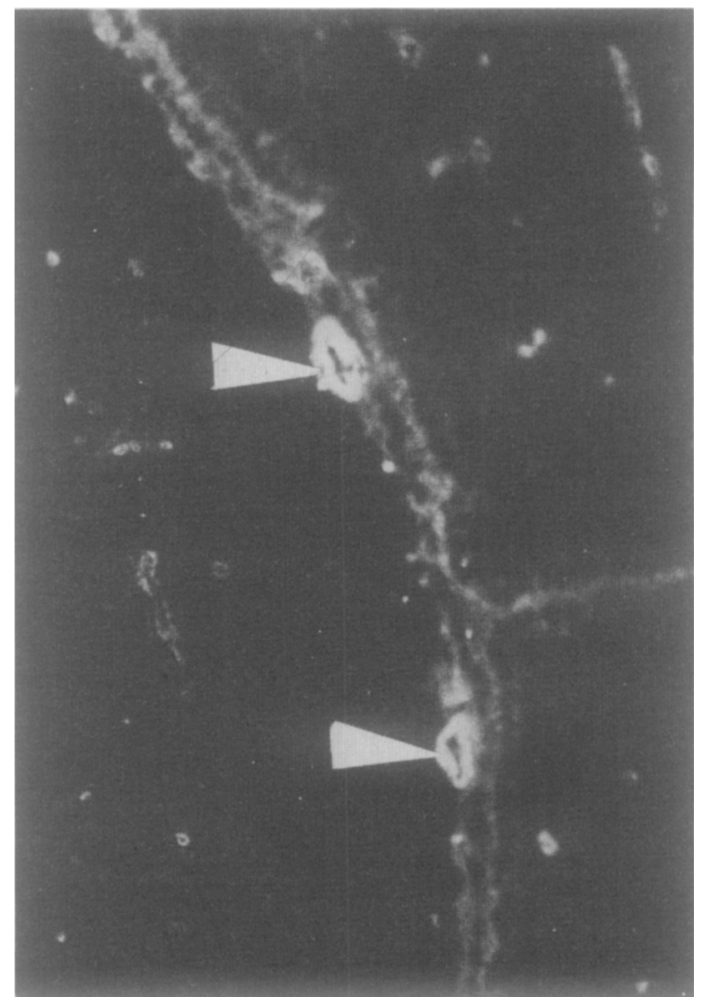

Fig. 4. Two fluorescent capillaries (arrows) on the meninges of a

\begin{tabular}{|c|c|c|c|c|c|c|}
\hline \multirow[b]{2}{*}{ Infection } & \multirow[b]{2}{*}{ No. } & \multirow[b]{2}{*}{ Day } & \multicolumn{2}{|c|}{$\mathrm{CIC}$} & \multirow[b]{2}{*}{$\begin{array}{l}\text { Intracerebral } \\
\text { IgG synthesis* }\end{array}$} & \multirow[b]{2}{*}{$\begin{array}{c}\text { Impairmen } \\
\text { of } B B B\end{array}$} \\
\hline & & & Serum & CSF & & \\
\hline+ & 48 & 34 & + & 0 & $-0 . \overline{44}$ & None \\
\hline+ & 33 & 35 & + & 0 & +0.1 & None \\
\hline+ & 52 & 52 & + & 0 & +1.5 & None \\
\hline Relapse & 52 & 129 & + & 0 & $+17 \cdot 0$ & Slight \\
\hline Cured & T16 & $>300$ & $n$ & 0 & $+8 \cdot 2$ & None \\
\hline
\end{tabular}
frozen mouse brain serving as antigenic substrate for detection of circulating antibodies in cerebrospinal fluid (diluted 1:10) of Monkey No. 52. Fluorescein-conjugated anti-human $\operatorname{IgG}, \times 80$.

Table II-Circulating immune complexes, (CIC) intracerebral immunoglobulin synthesis (IgG) and impairment of blood brain barrier (BBB) in trypanosome-infected vervet monkeys

Key:

\begin{tabular}{|c|c|c|c|c|c|c|c|}
\hline \multirow[b]{2}{*}{ Infection } & \multirow[b]{2}{*}{ No. } & \multirow[b]{2}{*}{ Day } & \multicolumn{2}{|c|}{$\operatorname{Ig} M$} & \multicolumn{2}{|c|}{ IgG } & \multirow[b]{2}{*}{ Author } \\
\hline & & & Serum $g / l$ & $\overline{\mathrm{CSF}} \mathrm{mg} / 1$ & $\overline{\text { Serum } \mathrm{g} / \mathrm{l}}$ & $\mathrm{CSF} \mathrm{mg} / \mathrm{l}$ & \\
\hline $\begin{array}{l}0 \\
+\end{array}$ & & & $\begin{array}{c}0 \cdot 85.3 \cdot 35 \\
15-35\end{array}$ & $\overline{\div 276}$ & $\begin{array}{l}15-40 \\
30-50\end{array}$ & $\begin{array}{r}5-50 \\
\div 296\end{array}$ & $\begin{array}{l}\text { FINK } \\
\text { et al. }\end{array}$ \\
\hline $\begin{array}{c}+ \\
+ \\
+ \\
\text { Relapse } \\
\text { Cured }\end{array}$ & $\begin{array}{r}48 \\
33 \\
52 \\
52 \\
\text { T16 }\end{array}$ & $\begin{array}{r}34 \\
35 \\
52 \\
129 \\
>300\end{array}$ & $\begin{array}{c}5 \cdot 2 \\
4 \cdot 6 \\
5 \cdot 2 \\
5 \cdot 0 \\
22 \cdot 8\end{array}$ & $\begin{array}{r}28 \\
0 \\
0 \\
141 \\
0\end{array}$ & $\begin{array}{l}21 \cdot 7 \\
26 \cdot 2 \\
35 \cdot 2 \\
23 \cdot 4 \\
24 \cdot 5\end{array}$ & $\begin{array}{r}64 \\
29 \\
45 \\
211 \\
113\end{array}$ & $\begin{array}{l}\text { POLTERA } \\
\text { et al. }\end{array}$ \\
\hline
\end{tabular}

$\star=\mathrm{mg} / 100 \mathrm{ml} \mathrm{CSF}$

$\mathrm{n}=$ normal value

No. $48=$ infected control

No. $\mathrm{T} 16=$ cured control

Table III-Blood and CSF immunoglobulins in trypanosome-infected vervet monkeys 
Table II illustrates that the blood-brain-barrier is only impaired in one animal but the intracerebral IgG synthesis is positive for the two relapse animals. Monkey No. 48 served as an infected control without encephalitis (but choroid plexitis), since it died from marked pancarditis. Monkey T16 was first treated with Diamidine Erlangen 102/198 on day 64 for four days but relapsed and was then treated with Melarsoprol on days 96 to 99 . In both situations the dosage was $5 \mathrm{mg} / \mathrm{kg}$ i.m. The monkey remained negative for parasites in blood and CSF for more than 200 days and it served as a cured control. Although CIC were normal in the serum the synthesis for intracerebral IgG was positive; there was no impairment of the blood-brain-barrier.

The absence of positive CIC levels in the CSF of all animals is to be noted.

The immunoglobulin (IgM and IgG) results in the serum and the CSF of the two relapses (Nos. 33, 52) are depicted in Table III using the same controls as in Table II. The table further indicates the range for normal and trypanosome-infected vervet monkeys as reported by FINK et al. (1983). It is evident that the values in monkey No. 52 after relapse (day 129) are frankly positive in the CSF, whereas at day 52before treatment-they were not. All except the cured monkey had positive IgM levels in the serum. The untreated animal with trypanosomal pancarditis and trypanosomal choroid plexitis (No. 48) showed positive results for immunoglobulins in the CSF.

Before killing two animals (Nos. 33, 52), the serum and CSF samples were tested for autoantibodies with a freshly frozen mouse brain serving as antigenic substrate. Positive reactions were observed on the small blond vessels of the meninges and parenchyma with the serum and CSF of the monkey which survived (No. 52, Fig. 4) but not with the choroid plexus. In the other case (No. 33) the serum only stained small blood vessels of the brain parenchyma and the CSF faintly marked the blood vessel of a choroid plexus. Neurones were not stained in either of these two cases.

Discussion
The present results show the usefulness of a chemotherapeutic model which is based on CSF infiltration by trypanosomes before test drugs are administered. Although virulent trypanosomes were used, the trypanocide in case of relapse may alter the clinical course since the post-therapeutic survival time may exceed the average survival time of untreated monkeys. Hence a critical and patient long term follow-up of treated trypanosome-infected hosts is essential before cure is declared. Improvement in tissue techniques permitted visualization of trypanosomes, particularly with immunofluorescence (POLIERA et al., 1980, 1981, 1982) and electron microscopy (RUDIN et al., 1983), organ transfer experiments (JENNINGS et al., 1979) and tissue elution techniques (MULUMBa \& WéRY, 1983). It appears that trypanosomes shift from a choroid plexus and meningeal invasion to intracerebral, extracellular-interstitial localization in relapse cases (POLTERA et al., 1981, 1982).

These "persister" trypanosomes have been found interstitially by $E M$ in several chemotherapeutic models (RUDIN et al., 1983) and they appear morpho- logically to be perfectly viable. Apparently trypanosomes manage to adapt biochemically to this environment. The spontaneous occurrence of interstitial intracerebral trypanosomes has also been reported (FINK \& SCHMIDT, 1979; VAN MARCK et al,, 1981; POLTERA et al., 1982). Probably the cerebral interstitium constitutes a site protected from a major immune response and most trypanocides. It would be of interest to know if neuroleptic phenothiazines also prove trypanolytic in vivo, and notably in the CNS, as opposed to the reported in vitro action (SEEBECK \& GEHR, 1983).

Although antigenic variation is considered to be the major escape mechanism of the trypanosome from the immune response, "hiding" places such as the cerebral interstitium and possibly endocardial valves (Poltera et al., 1985) ought to be considered.

In addition the morphology of the trypanosome appears to play a role in establishing relapses after chemotherapy (GRAY et al., 1982). The common denominator of relapses following various trypanocides (CAlWELl, 1937; MCCully \& NeITZ, 1971; POLTERA et al., 1981, 1982; SCHMIDT \& SAYER, 1982; POLTERA, 1983) is the diffuse encephalitis, characterized mainly by a vasculitis. This cerebral vasculitis is either spontaneously achieved, for example in HAT (POLTERA et al., 1977), or experimentally drug induced as already quoted.

Circulating immune complexes $(=\mathrm{CIC})$ have been described in HAT (FRUIT et al., 1977; WHITTLE et al., 1980; LAMBERT et al., 1981) and in EAT (GAlvaO-CASTRO et al., 1978; Pol TERA et al., 1980). After single dose chemotherapy in EAT, CIC tend to increase (POLTERA et al., 1981) and their response can be immunomodulated (Pol TERA et al., 1984). Immune complexes can mediate vasculitis and in EAT deposits of immune complexes have been shown to occur in blood vessels including the CNS (POLTERA et al., 1980; VAN MARCK et al., 1983). Since CIC were demonstrated in CSF of HAT (LAMBERT et al., 1981), their participation in blood-brain-barrier alterations may be considered. Subsequent to the report of smooth muscle antibodies in HAT caused by $T$. gambiense (see WOLGA et al., 1981) this study gives experimental evidence that such antibodies to blood vessels do occur in the blood and CSF of trypanosome-infected monkeys.

Since the partially suppressed antibody response in EAT is restored within hours after single dose therapy with Berenil ${ }^{R}$ (ROELANTS et al., 1979) the increase of CIC and antibodies to blood vessels may contribute to the vascular leakage-be it oedematous or haemorrhagic - as seen in EAT (POLTERA et al., 1981) or in HAT (MANUELIDIS et al., 1956; HALLER et al., in press). The present and published data (LAMBERT $e t$ al., 1981) do show a blood-brain-barrier impairment in advanced sleeping sickness and this may be aggravated by certain trypanocides. Only further, more extensive, studies of such available models will clarify the interaction of disease stage, immune response and new trypanocides with, it is hoped, fewer side effects or find ways to control the side cffects of existing trypanocides.

\section{Acknowledgements}

These investigations received financial support from the UNDP/World Bank/WHO special Programme for Research 
and Training in Tropical Diseases as well as from the Swiss Government (Dr. A. A. Poltera). In addition the generous assistance of the Departments of Pathology from the Veterinary Research Station, Muguga, Kenya and the International Laboratory for Research in Animal Diseases, Nairobi, is gratefully acknowledged. Our sincere thanks to all the people involved and to Miss P. Hess for secretarial assistance.

\section{References}

Calwell, H. G. (1937). The pathology of the brain in Rhodesian trypanosomiasis. Transactions of the Royal Society of Tropical Medicine and Hygiene, 30, 611-624.

Fink, E. \& Schmidt, H. (1979). Meningoencephalitis in chronic Trypanosoma brucei rhodesiense infection of the white mouse. Tropenmedizin und Parasitologie, 30, 206211.

Fink, E.,Sayer, P. \& Schmidt, H. (1983). IgG and IgM-Levels in Serum and CSF of $T$. rhodesiense infected vervet monkeys. Contributions to Microbiology and Immunology, 7, 183-189 (Basel: Karger).

Fruit, J., Santoro, F., Afchein, D., Duvallet, G. \& Capron, A. (1977). Les immunocomplexes circulants dans la trypanosomiase africaine humaine et expérimentale. Annales de la Société belge de Médecine tropicale, 57, 257-266.

Galvao Castro, B., Hochmann, A. \& Lambert, P. H. (1978). The role to the host immune response in the development of tissue lesions associated with African trypanosomiasis in mice. Clinical and Experimental Immunology, $33,12-24$

Gray, G. D., Jennings, F. W. \& Hajduk, S. L. (1982). Relapse of monomorphic and pleomorphic Trypanosoma brucei infections in the mouse after chemotherapy. Zeitschrift für Parasitenkunde, 67, 137-145.

Haller, L., Adams, H., Merouze, F. \& Dago, A. Clinical and pathological aspects of African human trypanosomiasis with particular references to reactive arsenical encephalopathy.

Jennings, F. W., Whitelaw, D. D., Holmes, P. H., Chizyuka, H. G. B. \& Urquhart, G. M. (1979). The brain as a source of relapsing Trypanosoma brucei infection in mice after chemotherapy. International fournal for Parasitology, 9, 381-384.

Lambert, P. H., Berney, M. \& Kazyumba, G. L. (1981). Immune complexes in serum and in cerebrospinal fluid in sleeping sickness. Correlation with polyclonal B-cell activation and with intracerebral immunoglobulin synthesis. Foumal of Clinical Investigation, 67, 77-85.

McCully, R. M. \& Neitz, W. O. (1971). Clinicopathological study on experimental Trypanosoma brucei infections in horses. Part 2. Histopathological findings in the nervous system and other organs of treated and untreated horses reacting to nagana. Onderstepoort Foumal of Veterinary Research, 38, 141-176.

Manuelidis, E. A., Robertson, D., Amberson, J., Polak, M. \& Haymaker, W. (1956). Trypanosoma rhodesiense encephalitis-clinicopathological study of five cases of encephalitis and one of Mel B hemorrhagic encephalopathy. Acta Neuropathologica, 5, 176-204.

Mulumba, P. M. \& Wéry, M. (1983). Experimental infection with two stocks of Trypanosoma brucei gambiense. Study of the evolution by elution techniques of tissues. Contributions to Microbiology and Immunology, 7, $120-129$.

Neitz, W. O. \& McCully, R. M. (1971). Clinicopathological study on experimental Trypanosoma brucei infections in horses. Part 1. Development of clinically recognizable nervous symptoms in nagana-infected horses treated with subcurative doses in Antrypol and Berenil. Onderstepoort Fournal of Veterinary Research, 38, 127-140.

Poltera, A. A., Owor, R. \& Cox, J. N. (1977). Pathological aspects of human African trypanosomiasis (HAT) in Uganda. A post-mortem survey of fourteen cases. Virchows Archiv für pathologische Anatomie und Histologie, $373,249-265$.
Poltera, A. A., Hochmann, A., Rudin, W. \& Lambert, P. H. (1980). Trypanosoma brucei brucei: a model for cerebral trypanosomiasis in mice. An immunological, histological and electronmicroscopic study. Clinical and Experimental Immunology, 40, 496-507.

Poltera, A. A., Hochmann, A. \& Lambert, P. H. (1981). Trypanosoma brucei brucei: the response to Melarsoprol in mice with cerebral trypanosomiasis. An immunopathological study. Clinical and Experimental Immunology, 46, 363-374.

Poltera, A. A., Hochmann, A. \& Lambert, P. H. (1982). Trypanosoma brucei gambiense: cerebral immunopathology in mice. Acta Tropica, 39, 205-218.

Poltera, A. A. (1983). Chemotherapy, relapses and CNS in experimental African trypanosomiases. Contributions to Microbiology and Immunology, 7, 155-164.

Poltera, A. A., Mbuya, B. K., Nkonge, C., Brighouse, G., Musoke, A. J., Nantulya, V. M. \& Montanari, C. (1984). Trypanosoma brucei brucei: Immunosuppressive Modulation von zirkulierenden Immunkomplexen nach einmaliger Verabreichung von Melarsoprol bei 6-wöchiger experimenteller Infektion. In: Tropenmedizin, Parasitologie. Boch J. (Editor). [Medizin in Entwicklungsländern Band 16] Frankfurt a/M.: Verlag Peter Lang pp. 79-86.

Poltera, A. A., Sayer, P. D., Rudin, W. \& Bovell, D. (1985). Trypanosomal cardiac valvulitis in vervet monkeys. Tropenmedizin und Parasitologie, 36, (in press).

Roelants, G. E., Pearson, T. W., Morrison, W. I., Mayor-Withey, K. S. \& Lundin, L. B. (1979). Immune depression in trypanosome infected mice. IV Kinetics of suppression and alleviation by the trypanocidal drug Berenil. Clinical and Experimental Immunology, 37, 457-469.

Rudin, W., Poltera, A. A. \& Jenni, L. (1983). An EM study of cerebral trypanosomiasis in rodents and primates. Contributions to Microbiology and Immunology, 7, 165-172.

Schmidt, H. \& Bafort, J. M. (1985). African trypanosomiasis: treatment-induced of brain and encephalitis. American Joumal of Tropical Medicine and Hygiene, 34, 64-68.

Schmidt, H. \& Sayer, P. D. (1982). Trypanosoma brucei rhodesiense infection in vervet monkeys. I. Parasitologic, haematologic, immunologic and histologic results. II. Provocation of the encephalitic late phase by treatment of infected monkeys. Tropenmedizin und Parasitologie, 33, 249-254, 255-259.

Seebeck, T. \& Gehr, P. (1983). Trypanocidal action of neuroleptic phenothiazines in Trypanosoma brucei. Molecular and Biochemical Parasitology, 9, 197-208.

Van Marck, E. A. E., Le Ray, D., Beckers, A., Jacob, W. Wéry, M. \& Gigase, P. L. J. (1981). Light and electron microscope studies on extravascular Trypanosoma bricei gambiense in the brain of chronically infected rodents. Annales de la Société belge de Médecine tropicale, 61, 57.78.

Van Marck, E. A. E., Mulumba, P., Beckers, A., Gigase, P. $\&$ Wéry, M. (1983). Studies of choroid plexus involvement in chronic infections of mice infected with Trypanosoma brucei gambiense. Contributions to Microbiology and Immunology, 7, 173-182.

Whittle, H. C., Mohammed, I. \& Greenwood, B. M. (1980) Immune complexes in Gambian sleeping sickness. Transactions of the Royal Society of Tropical Medicine and Hygiene, 74, 833-834.

Wolga, J. I., Daniel-Ribeiro, C., Gaillat, J., Stahl, J. P., Micoud, M. \& Gentilini, M. (1981). Autoanticorps dans les trypanosomiases africaines. Anticorps anti-muscle lisse au cours d'une maladie à Trypanosoma gambiense. Bulletin de la Société de Pathologie Exotique, 74, 676-684.

Accepted for publication 15th February, 1985. 